\title{
Ferenczi e sua Técnica: um Novo Olhar sobre a Transferência
}

\author{
Ferenczi and his Technique: a Fresh Look on Transference
}

\author{
Marina Tente Silva' (orcid.org/0000-0002-5346-6483) \\ Fátima Siqueira Caropreso² (orcid.org/0000-0002-8197-1479)
}

\begin{abstract}
Resumo
A transferência é um processo fundamental para a Psicanálise. Entre os principais autores que investigaram o fenômeno transferencial, baseados em um referencial psicanalítico, o psicanalista húngaro Sándor Ferenczi se destaca. A importância de sua contribuição, contudo, ainda permanece pouco reconhecida na literatura psicanalítica. Esse autor demonstrou que o tratamento padrão psicanalítico, muitas vezes, não conseguia produzir os efeitos esperados e que algumas inovações técnicas eram necessárias. O presente artigo tem como objetivo analisar o conceito de transferência nos textos do referido autor, bem como as relações entre sua visão da transferência e as mudanças na técnica por ele introduzidas. Em um primeiro momento, apresentamos e discutimos o conceito de transferência e sua relação com o conceito de introjeção, em seguida, voltamo-nos para as modificações técnicas ferenczianas, buscando apontar as implicações destas para sua concepção do fenômeno transferencial.
\end{abstract}

Palavras-chave: Psicanálise. Sándor Ferenczi. Transferência. Introjeção. Técnica psicanalítica.

\begin{abstract}
Transference is a fundamental process for Psychoanalysis. Among the main authors who investigated transferential phenomenon, based on a psychoanalytic viewpoint, the Hungarian psychoanalyst Sándor Ferenczi stands out. The importance of his contribution, however, still remains unappreciated in psychoanalytic literature. This author demonstrated that standard psychoanalytic treatment often failed to produce the expected effects and that some technical innovation were necessary. This article aims to analyze the concept of transference in the texts of this author, as well as the relationship between his views on transference and the changes in technique introduced by him. At first, we present and discuss the concept of transference and its relationship with the concept of introjection, and then we turn to Ferenczian technical modifications, seeking to point out the implications of these for his conception of the transferential phenomenon.
\end{abstract}

Keywords: Psychoanalysis. Sándor Ferenczi. Transference. Introjection. Psychoanalytic techniques.

\footnotetext{
${ }^{1}$ Universidade Federal de Juiz de Fora, Juiz de Fora, Brasil. E-mail: marinatentesilva@gmail.com.

${ }^{2}$ Universidade Federal de Juiz de Fora, Juiz de Fora, Brasil. E-mail: fatimacaropreso@uol.com.br.
} 


\section{Introdução}

O fenômeno da transferência é primeiramente mencionado no último ensaio dos Estudos sobre a histeria, escrito por Sigmund Freud e Joseph Breuer (1895/1996). Freud (1914/1996) esclarece que a descoberta da transferência se deu de forma indireta a partir de um "fato inconveniente" que the foi revelado por Breuer acerca do caso de Anna O. Maurano (2006) comenta que, nesse caso, ocorreram vários eventos desastrosos, principalmente devido ao não reconhecimento de como a sexualidade estava imbricada tanto na causação dos sintomas quanto na relação transferencial. Laplanche e Pontalis (2001) ressaltam que a transferência demonstrou a extensão dos seus efeitos antes mesmo de o terapeuta saber como identificá-la e utilizá-la.

Em Fragmento da análise de um caso de histeria (Freud, 1905[1901]/1992), no Caso Dora, a ideia de transferência surge como primordial. No posfácio desse trabalho, Freud justifica-se sobre um defeito na interpretação da transferência que teria gerado a interrupção prematura do tratamento. Percebemos como a intensidade do fenômeno transferencial demonstrava sua força, mesmo que ainda não houvesse aparato clínico e teórico para manejá-la. O próprio autor esclarece que foi obrigado a falar em transferência porque somente por meio dela conseguiu esclarecer as particularidades do caso, a partir do qual pôde observar que a relação transferencial modula tanto o tratamento quanto os sintomas do paciente.

A progressiva integração do complexo de Édipo na teorização psicanalítica fez com que Freud percebesse que é, sobretudo, a relação do sujeito com as figuras parentais que é revivida na transferência e que esta pode apresentar-se como "positiva" ou "negativa". Freud constatou que a transferência para a pessoa do médico aparece quando conteúdos recalcados ameaçam se revelar. Dessa forma, a partir do momento em que colocou em evidência os protótipos dos conflitos infantis do sujeito, a transferência passou a ser considerada um processo estruturante do tratamento psicanalítico (Freud,1912a/1996).

Entre os principais autores que investigaram o fenômeno transferencial, baseandose em um referencial psicanalítico, destaca-se o psicanalista húngaro Sándor Ferenczi. Segundo Casadore (2012), no ano de 1908, Ferenczi já havia iniciado sua produção bibliográfica pautada na Psicanálise e nos círculos médicos de Budapeste demonstrava seu interesse e defendia veementemente o novo método terapêutico, mesmo diante de fortes críticas. Ferenczi propôs inúmeros questionamentos e experimentos clínicos sobre a técnica psicanalítica clássica. Nesse sentido, Brusset (2011) ressalta que, desde muito cedo, ele demonstrou que o tratamento padrão psicanalítico não conseguia produzir os efeitos esperados e que muitas inovações eram pertinentes. A maioria dos quadros atendidos por Ferenczi era grave e não podia ser tratado a partir das técnicas tradicionais da Psicanálise, o que o impulsionou a buscar novas estratégias terapêuticas.

Kupermann (2010) comenta que as reflexões sobre a técnica e a correção constante, propostas por Ferenczi, podem ser vistas como resultantes do fato de que ele tratava pacientes em severo sofrimento psíquico. Isso teria lhe permitindo formular um estilo clínico adequado ao 
manejo transferencial desses analisandos. Em outro trabalho, o mesmo autor (Kupermann, 2008) aponta que as inovações de Ferenczi buscavam a adaptação do psicanalista ao ritmo e aos rumos do processo de subjetivação do analisando e, além disso, a adaptação da própria Psicanálise às diferentes formas de sofrimento psíquico e às demandas da intervenção clínica.

Rachman (2007) ressalta que a análise das contribuições de Ferenczi para a evolução da Psicanálise é necessária, não apenas para corrigir um descuido histórico, mas também para possibilitar a continuidade do diálogo sobre as questões importantes que ele começou a examinar.

$\mathrm{O}$ presente artigo tem como objetivo analisar o desenvolvimento do conceito de transferência nos textos do referido autor, bem como as relações entre a transferência e as inovações técnicas por ele propostas. Em um primeiro momento, apresentamos e discutimos o conceito de transferência e sua relação com o conceito de introjeção, em seguida, voltamo-nos para suas modificações técnicas, tentando apontar as implicações destas para sua concepção do fenômeno transferencial.

\section{Transferência e Introjeção}

As primeiras elaborações de Ferenczi sobre a transferência estão presentes em seu artigo Transferência e Introjẹcão (Ferenczi, 1909/2011). Percebemos nele o processo de aproximação entre Ferenczi e Freud e a utilização da definição de transferência apresentada por Freud (1905[1901]/1992). Nesse trabalho, Ferenczi argumenta que a tendência a transferir dos psiconeuróticos se manifesta em todos os âmbitos da vida e se apresenta como um mecanismo característico da neurose. $\mathrm{O}$ tratamento psicanalítico seria muito propício para o estabelecimento da transferência, uma vez que os afetos, até então recalcados, iriam sendo despertados e se deparariam com a pessoa do médico.

Ferenczi (1909/2011) comenta que a análise demonstrou haver uma associação entre a figura do médico e fantasias sexuais infantis. Segundo ele, devido ao complexo de Édipo, o médico passaria a fazer parte das "séries psíquicas" de seus pacientes, evocando as figuras de sua infância, seus primeiros objetos de amor: os pais. Além disso, o próprio comportamento do analista, por vezes compreensivo e benevolente, poderia gerar em seus pacientes tais fantasias inconscientes. Portanto, reconhecer tanto as transferências de sentimentos positivos quanto negativos seria imprescindível na análise, uma vez que, à medida que ela progredisse, o paciente iria dissociando suas emoções desproporcionais dos motivos atuais e projetando-as em pessoas mais importantes.

No mesmo texto, Ferenczi (1909/2011) retoma a concepção freudiana sobre a formação da neurose, de acordo com a qual toda neurose seria uma manifestação indireta de complexos inconscientes. Na tentativa de escapar de um conflito resultante de impulsos que originalmente visavam ao prazer, mas acabaram se convertendo em fontes de desprazer, devido ao surgimento de uma incompatibilidade com o ego, os neuróticos reprimiriam tais impulsos, os quais, no entanto, voltariam a se manifestar, de forma substitutiva, nos sintomas. O processo em questão consistiria na retirada da libido de um 
complexo que teria se tornado incompatível com o ego, entretanto, essa retirada não seria total, uma vez que apenas o interesse consciente pelo objeto de amor ou de ódio desapareceria. Ferenczi (1909/2011) aponta que o psiquismo do neurótico, contudo, não consegue lidar bem com os afetos "livremente flutuantes" desinvestidos do complexo. Haveria sempre uma quantidade variável de excitação livre que subsistiria e seria direcionada para os objetos do mundo externo. Sobre esse aspecto, o autor esclarece:

É a essa quantidade de excitação "residual" que se imputará a disposição dos neuróticos para a transferência; e nas neuroses sem sintoma permanente de conversão é essa libido insatisfeita, em busca de objeto, que explica o conjunto do quadro patológico. (Ferenczi, 1909/2011, p. 94, grifos nossos)

Portanto, a transferência se daria a partir da excitação livre, que não poderia ser satisfeita e se voltaria para o mundo externo. Segundo Ferenczi (1909/2011), os neuróticos procurariam incluir em sua esfera de interesses uma parte tão grande quanto possível do mundo externo. Esse processo poderia ser traduzido como Suchtigkeit, ${ }^{3}$ que é considerado um processo de diluição, mediante o qual o neurótico procuraria atenuar as sensações penosas dessas aspirações "livremente flutuantes", insatisfeitas e impossíveis de satisfazer (Ferenczi, 1909/2011, p. 95). Esse fenômeno é denominado "introjeção". Segundo ele:

\footnotetext{
3 Segundo os tradutores franceses, Ferenczi teria recorrido ao termo alemão para exprimir a ideia que definiu como "impulso", "tendência" e "aspiração".
}

O neurótico está em uma perpétua busca de objetos de identificação, de transferência; isso significa que atrai tudo o que pode para a sua esfera de interesses, "introjeta-os". [...] O neurótico interessa-se por tudo, distribui seu amor e seu ódio pelo mundo inteiro [...]. O "ego" do neurótico é patologicamente dilatado [...]. (Ferenczi, 1909/2011, p. 95)

Dessa maneira, a introjeção é concebida como um processo por meio do qual os neuróticos tentam neutralizar os afetos flutuantes, transferindo-os para objetos do mundo externo, expandindo sua esfera de interesses - seu ego.

Laplanche e Pontalis (2001, p. 248), em "Vocabulário de Psicanálise", comentam que Ferenczi foi o responsável por introduzir o termo "introjeção" na Psicanálise. No entanto, eles apontam como é difícil distinguir uma acepção exata da noção de introjeção em Ferenczi, uma vez que o termo é utilizado de forma muito ampla, como uma "paixão pela transferência" dos neuróticos, a fim de amenizar os afetos flutuantes. Eles ressaltam, em contrapartida, a utilização específica que Freud faz do termo, ao usá-lo para designar o processo oposto à projeção.

Os mecanismos de introjeção e projeção ganham destaque em Transferência e Introjeção (Ferenczi, 1909/2011). Nesse texto, o autor elabora hipóteses sobre como o desenvolvimento libidinal estaria relacionado com tais processos. Segundo ele, inicialmente, o recém-nascido experimentaria todas as coisas de uma forma monista, seja um estímulo externo, seja um processo psíquico. Com o tempo, a criança aprenderia que algumas coisas não se submetem à sua vontade, enquanto outras $\mathrm{O}$ 
fazem. Dessa forma, o monismo seria transformado em um dualismo: os objetos sobre os quais ela não tem controle seriam excluídos de suas percepções e passariam a formar o mundo externo. Estes, pela primeira vez, se oporiam ao "ego", de forma que seria efetuada uma "projeção primitiva". Se, mais tarde, a criança desejasse desfazer-se de afetos desagradáveis, ela poderia expulsar uma parte maior do ego para o mundo externo. Porém, o mundo externo não se deixaria expulsar tão facilmente do ego e persistiria em impor-se, de forma que o ego, muitas vezes, teria que reabsorvê-lo. Segundo Ferenczi (1909/2011, p. 96), “o ego cede a esse desafio, reabsorve uma parte do mundo externo e a inclui em seu interesse: assim se constitui a primeira introjeção, 'a introjeção primitiva"'. Assim, ele define a introjeção primária como uma reabsorção de uma parte do ego que foi anteriormente projetada. Haveria, assim, uma projeção primária que seria seguida por uma introjeção primária.

Em uma importante nota de rodapé, Ferenczi (1909/2011) parece já prever os equívocos que a introdução do termo introjeção e sua relação com o conceito de transferência poderia gerar. Ele diz que o termo "transferência", criado por Freud, foi utilizado apenas para designar as introjeções que se manifestam ao longo de uma análise e que visam ao médico, em virtude de sua extrema importância prática. No entanto, o autor argumenta que o termo "introjeção" deveria ser utilizado para todos os outros casos que implicassem o mesmo mecanismo.
Pinheiro (2016) ressalta a importância da proposição do conceito de introjeção na obra de Ferenczi, uma vez que tal conceito pode ser considerado um norteador de toda produção teórica posterior do autor. Além disso, destaca que a introjeção consiste em um processo psíquico originário, que pode ser considerado o precursor fundamental do conceito de narcisismo de Freud.

Buscando ampliar as proposições de Transferência e Introję̧ão, Ferenczi (1909/2011) escreve $O$ conceito de introjeção (1912a/2011). Neste, a introjeção é definida como uma extensão ao mundo externo do interesse, que, em sua origem, é autoerótico, a partir da introdução de objetos externos no ego, como já havia proposto anteriormente. $\mathrm{Na}$ seguinte passagem ele esclarece: "Insisti nessa 'introdução', para sublinhar que considero todo amor objetal (ou toda transferência) como uma extensão do ego ou introjeção, tanto no indivíduo normal quanto no neurótico [...]” (Ferenczi, 1912a/2011, p. 209). Logo, toda transferência seria uma introjeção, uma introdução dos objetos externos no ego, bem como todo amor objetal seria uma transferência. Verztman (2002) aponta que o processo introjetivo deveria ser responsável pela capacidade da criança de se inserir no mundo, a partir da ampliação da capacidade do seu eu de criar laços de dependência com outros.

Tendo em vista essas hipóteses, Ferenczi (1912a/2011) afirma que o homem só pode amar a si mesmo, já que amar outra pessoa equivale a integrá-la em seu próprio ego. Nas palavras do autor, "Em última análise, o homem só pode amar-se a si mesmo e a mais ninguém; 
amar a outrem equivale a integrar esse outrem no seu próprio ego.” (Ferenczi, 1912a/ 2011, p. 209).

Nesse ponto, o autor propõe que é justamente a união entre os objetos amados e a própria pessoa, a fusão entre os objetos e o ego, que deveria ser designada como introjeção. Ele comenta: “[...] acho que o mecanismo dinâmico de todo amor objetal e de toda transferência para um objeto é uma extensão do ego, uma introjeção" (Ferenczi, 1912a/2011, p. 210). De acordo com essas hipóteses, o mecanismo da transferência seria o mecanismo da introjeção.

\section{A Transferência e as Modificações Técnicas}

O interesse de Ferenczi voltou-se cada vez mais para técnicas que pudessem auxiliá-lo no tratamento de pacientes difíceis e a sua concepção de transferência foi extremamente influenciada por essas propostas. Tendo em vista suas inovações técnicas, destaca-se o trabalho $A$ técnica psicanalitica (Ferenczi, 1919a/2011), no qual encontramos a primeira menção sobre o uso da "técnica ativa", ainda que de forma pontual. $\mathrm{O}$ autor aborda, nesse trabalho, a utilização das técnicas psicanalíticas e aponta algumas dificuldades clínicas com as quais se deparou. 4

Ferenczi (1919a/2011) comenta que, diante de certos casos, o médico deveria limitarse a um "confessor analítico", intervindo em raras exceções. Uma de tais exceções seria a possibilidade de utilizar a "terapia ativa" para

\footnotetext{
4 Em carta a Ferenczi de 13 de fevereiro de 1919, Freud teria expressado a importância de tal trabalho qualificando-o como "puro ouro analítico" (Hoffer, 2000).
}

que o paciente pudesse superar sua incapacidade de tomar uma decisão em sua vida. Ele aponta como o trabalho do analista é árduo, pois exige saber dosar seus atos, falas e sentimentos, sem deixar-se cair no extremo oposto e impossibilitar o surgimento da transferência, demonstrando uma postura fria e distante. Para lidar com tais situações, o analista deveria já ter sido analisado, ou seja, deveria ser capaz de controlar a contratransferência gerada pelo afluxo afetivo presente na análise, ressalta o autor.

Em Dificuldades técnicas de uma análise de histeria (Com observações sobre o onanismo larvado e os "equivalentes masturbatórios"), texto ferencziano que também data de 1919, podemos perceber como, em tão pouco tempo, suas ideias se avolumaram e, por vezes, já começaram a se distanciar de Freud. Como aponta Dupont (1974/2011), dois fatos importantes marcaram esse período da vida e da obra de Ferenczi: o desenvolvimento da técnica ativa e o início das discordâncias com Freud. Encontramos, no artigo em questão, a primeira descrição clínica mais detalhada do uso da técnica ativa - que havia sido apenas citada no trabalho anterior -, a qual prepararia o longo caminho para os artigos que se seguiriam sobre o tema. Nesse texto, têm início as divergências de opinião entre Ferenczi e Freud. Este teria apoiado as primeiras experiências de atividade de Ferenczi, e até reivindicado a paternidade da ideia, porém, logo as recusou.

As observações e dificuldades na análise de uma paciente histérica são relatadas nesse trabalho. Ferenczi (1919b/2011) mostra como tal paciente refugiava-se do trabalho analítico sob o amor de transferência. No decorrer do tratamento, viu-se levado a refletir sobre o tema do onanismo e acabou proibindo certos 
comportamentos de sua paciente. Segundo ele, o efeito da interdição teria sido "fulminante", levando-o a perceber que, a partir da proibição de todas as formas de onanismo, a libido era privada de todo e qualquer tipo de descarga. A paciente, que dissipava toda sua sexualidade nesses atos, pôde, com o tratamento, renunciálos e, assim, sua sexualidade ficou livre para encontrar o caminho da zona genital, explica o autor (Ferenczi, 1919b/2011).

Diante dessas constatações, Ferenczi (1919b/2011) relata que foi levado a abandonar o papel passivo que o psicanalista desempenha habitualmente no tratamento. Ajudou sua paciente a ultrapassar "os pontos mortos" do trabalho analítico, a partir da intervenção ativa em seus mecanismos psíquicos. $\mathrm{O}$ autor comenta sobre a "técnica ativa":

Espera-se assim que as valências no princípio não saturadas desses afetos que passaram a flutuar livremente atraiam, de forma prioritária, as representações que lhes são qualitativamente adequadas e historicamente correspondentes. Logo, também aqui se trata, como no nosso caso, de barrar as vias inconscientes e habituais de escoamento da excitação e de obter por coação o investimento préconsciente, assim como a versão consciente do recalcado. (Ferenczi, 1919b/2011, p. 7)

Dessa forma, a interdição, uma das técnicas ativas, buscava barrar as vias inconscientes e habituais de excitação, as quais geravam os "pontos mortos" do trabalho analítico. Como consequência, a libido poderia encontrar formas de tramitação qualitativamente mais adequadas, capazes de propiciar o desaparecimento dos sintomas.
Seguindo o desenvolvimento da técnica ativa, o segundo texto que se destaca é Prolongamentos da 'técnica ativa' em Psicanálise 5 (Ferenczi,1921/2011). Neste, o autor aponta que, a partir de certos artifícios observados em sua experiência clínica, pôde provocar ou acelerar a investigação do material psíquico inconsciente. Ele adverte que esses artifícios só deveriam ser utilizados em casos excepcionais e limitados ao estritamente necessário. Uma vez superados os momentos de estagnação da análise, o médico deveria voltar à sua "atitude de receptividade passiva" (Ferenczi, 1921/2011, p. 117).

Para o autor, a "atividade" era conhecida de longa data e teria desempenhado um papel importante nos primórdios da Psicanálise, jamais tendo deixado de existir. O período do método catártico, usado por Breuer e Freud, teria sido marcado por uma enorme atividade tanto do médico quanto do paciente. Havia um enorme esforço por parte do médico para despertar as lembranças ligadas aos sintomas das pacientes: por um lado, o médico utilizava várias técnicas; e, por outro, o paciente se esforçava para segui-las (Ferenczi, 1921/2011).

A partir desse contexto histórico, Ferenczi (1921/2011) delimita sua "técnica ativa" como uma intervenção muito mais ativa por parte do paciente do que do médico. O paciente teria um duplo trabalho: deveria manter-se na observância da "regra fundamental" e também executar algumas

\footnotetext{
5 Comunicação apresentada no VI Congresso da Associação Internacional de Psicanálise em Haia, 10 de dezembro de 1920.
} 
tarefas. $\mathrm{O}$ autor explica, a partir de um relato de caso, como utilizava essas tarefas:

Não demorei muito em ter a ocasião de impor a uma paciente tarefas que consistiam nisto: devia renunciar a certas ações agradáveis que tinham permanecido até então despercebidas (excitação masturbatória das partes, estereotipias e tiques, ou excitações de outras partes do corpo), dominar seu impulso para realizar esses atos. (Ferenczi, 1921/2011, p. 120)

No texto Perspectivas da psicanálise (Sobre a interdependência da teoria e da prática) (Ferenczi \& Rank, 1924a/2011), 6 os autores comentam que, naqueles últimos anos, havia uma desorientação crescente entre os analistas, principalmente, em relação aos problemas técnicos apresentados pela prática. Destacam que, apesar do desenvolvimento da teoria psicanalítica, a literatura negligenciou o fator técnicoterapêutico, que seria o núcleo de todo o processo e dos avanços na teoria. Eles apontam que mesmo o pai da Psicanálise havia tratado com muita reserva o tema da técnica psicanalítica em seus artigos técnicos. Sobre esse estado de coisas e sobre a forma como os analistas se orientavam, escrevem: "Por isso se

\footnotetext{
6 Os autores que compilaram o livro, no qual se encontra tal texto, assinalam que o capítulo II foi redigido somente por Rank e o capítulo III somente por Ferenczi. A sra. Ferenczi, por outro lado, acreditava lembrar-se de que os capítulos I e V também tivessem sido, essencialmente, escritos por Ferenczi. Observamos que na edição que utilizamos constam apenas três capítulos. Para fins práticos e reconhecendo os desenvolvimentos posteriores de Ferenczi, supusemos as passagens que fazem alusão à resistência, transferência negativa e favorecimento da compulsão à repetição no processo analítico como sendo de sua autoria. Otto Rank (1884-1939) foi psicanalista, escritor, professor e terapeuta austríaco. Por muitos anos, fez parte do círculo mais próximo de Freud.
}

explica que a maior parte desses analistas, reduzidos ao estudo da literatura, esteja aferrada com excessiva rigidez a essas regras técnicas, incapaz de articulá-las com os progressos registrados nesse meio-tempo pela ciência psicanalítica." (Ferenczi \& Rank, 1924a/2011, p. 244).

Além de outras coisas, este trabalho ressaltou a necessidade prática de não barrar as tendências à repetição na análise, buscando até mesmo favorecê-las. Só assim o material mais importante poderia aparecer e ser liquidado. Logo, a repetição tornaria possível que o material reprimido fosse liquidado progressivamente, transformando-o em lembranças atuais, a partir da relação atual do paciente e seu analista. Sobre a repetição, os autores afirmam: “[...] na técnica analítica, o papel principal parece, portanto, caber à repetição e não à rememoração" (Ferenczi \& Rank, 1924a/2011, p. 246).

$$
\text { Ferenczi e Rank }
$$
perceberam que o trabalho analítico deveria lidar cuidadosamente com as resistências. Segundo os autores, uma situação analítica que gerava muitos problemas era classificar, sob a etiqueta de "resistência", a transferência negativa. Esta só poderia manifestar sua natureza sob a forma de "resistência" e sua análise deveria ser a principal tarefa do tratamento analítico. As reações negativas do paciente não deveriam ser temidas, pois estariam presentes em todo processo analítico. Em toda análise normal, o analista poderia desempenhar todos os papeis possíveis para o inconsciente do paciente; caberia ao analista reconhecer esses papeis nos momentos oportunos e usá-los conscientemente. Esta seria uma das maiores contribuições ferenczianas para 
o edifício psicanalítico, o reconhecimento e a importância da transferência negativa (Kupermann, 2008; Pinheiro, 2016)

Balint (1970/2011) esclarece que Ferenczi tinha certa resistência em abandonar a técnica ativa, já que ela fornecia importante material clínico para suas deduções teóricas e êxitos terapêuticos. Decorrido algum tempo desde o início da "atividade", em Contraindicações da técnica ativa (Ferenczi, 1926/2011), um número considerável de fracassos é apresentado. Isso levou Ferenczi a erigir o seguinte: se um paciente desejasse prosseguir no tratamento, o analista deveria encontrar as técnicas necessárias para ajudá-lo nesse caminho.

Ferenczi (1926/2011) reconhece que a grande alegria causada pela descoberta daquele método com problemas psicológicos difíceis e, dessa forma, inoportunos, acabou levando-o a evitar aprofundar-se em seus trabalhos sobre a relação entre o aumento da tensão provocado pelos artifícios técnicos, por um lado, e a transferência e resistência, por outro. Como tentativa de reparação, esclarece que a atividade visava obter um novo material, uma vez que tinha como objetivo aumentar a tensão psíquica utilizando recusas, injunções e interdições. Entretanto, ela acabou por exacerbar a resistência do paciente, incitando seu ego a oporse ao analista. Em relação às consequências práticas de suas observações, constatou que a análise não devia iniciar pela atividade. O ego deveria ser poupado durante certo tempo e tratado com prudência, para que uma "sólida transferência positiva" pudesse se estabelecer. Ademais, o analista precisaria ser bastante experiente para avaliar o que poderia ser imposto ao paciente.

Ferenczi (1926/2011) passa a defender, então, que a atividade deveria ser utilizada apenas depois que todos os outros métodos existentes da "técnica não ativa" tivessem falhado. Relata que ele mesmo, por vezes, provocou uma série de outras dificuldades ao colocar, de modo rígido demais, certas injunções e proibições. Assim, pôde constatar que instruções formais acabariam levando o analista a impor forçosamente sua vontade ao paciente, numa repetição exagerada da situação pais/criança ou professor/aluno. Em meio a essas dificuldades, preferiu minimizar ou, até mesmo, renunciar a ordenar algumas coisas aos seus pacientes.

Apesar das limitações encontradas, Rachman (2007) destaca que, ainda hoje, é nítido o legado da abordagem ativa de Ferenczi. Segundo o autor, esta influenciou diversas perspectivas clínicas para o uso da abstinência no tratamento de dependências, o emprego de abordagens ativas na terapia comportamental e os compromissos clínicos ativos, característicos das psicoterapias infantis, conjugais e grupais.

A mobilização afetiva gerada pela análise e a necessidade de Ferenczi de oferecer novas possibilidades para seus pacientes - o furor sarandi - reverberava em suas experiências clínicas e em seus desenvolvimentos teóricos. Apostando em uma mudança em relação à técnica ativa, Ferenczi traz à tona o tema da elasticidade.

No texto Elasticidade da técnica psicanalítica (Ferenczi, 1928b/2011), o autor introduz a preciosa ideia de "tato psicológico". Sobre esta, 
ele esclarece o seguinte: “[...] com a palavra 'tato' somente consegui exprimir a indeterminação numa fórmula simples e agradável. Mas o que é o tato? [...] O tato é a faculdade de 'sentir com' (Einfublung)" (Ferenczi, 1928b/2011, p. 31). Para Ferenczi, o tato auxiliaria no discernimento de quando e como comunicar algo ao analisando, como deveria o analista reagir, como manejar os silêncios e as interpretações fornecidas. Assim, o tato seria a faculdade do analista de "sentir com" seu analisando e, dessa forma, poder modificar e flexibilizar sua técnica em relação às especificidades do seu sofrimento. $\mathrm{O}$ autor salientou que certa "bondade" apresentada pelo analista seria um dos aspectos que constituiria a tão cara compreensão analítica. De acordo com Pizzinga e Aran (2009), perceber e colocar em prática a habilidade de "sentir com" seria caminhar com equilíbrio diante das diversas formas de construir o dispositivo psicanalítico.

Para Abras (2014), todas as modificações técnicas ferenczianas eram sustentadas pela preocupação com a cura e pela certeza de que a análise não deveria ser cômoda para nenhum dos seus parceiros - analista e analisando. De fato, percebemos como Ferenczi (1928b/2011) empreendeu-se em uma tentativa de tornar sua técnica analítica elástica como uma tira: deveria esticar-se cedendo às tendências do paciente, sem abandonar sua tração sobre suas próprias opiniões. O analista deveria manter-se em uma oscilação constante entre "sentir com", auto-observação e atividade de julgamento. Nesse sentido, Rachman (2007) chama atenção para o fato de que Ferenczi teria sido o primeiro clínico a descobrir uma verdade essencial sobre a situação psicanalítica: a resposta empática é o núcleo da interação clínica.
Em seu percurso posterior, Ferenczi passou a modificar cada vez mais o princípio da frustação, inicialmente muito rigoroso, a fim de obter resultados mais profundos na análise. Progressivamente, voltou sua atenção para as tensões musculares, o que o levou, por vezes, a aconselhar exercícios de distensão para seus pacientes. Esse modo de relaxamento permitiria frequentemente superar com mais rapidez tanto as tensões psíquicas como as resistências à associação. Essas constatações acabaram conduzindo o autor a elaborar o trabalho Princípio de relaxamento e neocatarse (Ferenczi, 1930/2011).

$$
\text { Podemos dizer que Ferenczi }
$$

(1930/2011; 1933/2011; 1932/1990), gradualmente, foi percebendo que o cerne do seu dispositivo analítico baseava-se no encontro afetivo e na intensidade de sentimentos entre paciente e médico. Ressaltou que uma atitude fria e pedagógica por parte do analista com seu analisando influenciava o vínculo entre eles, podendo até mesmo rompê-lo. Ele destacou também que, a partir de uma relação "mais íntima", pôde compreender diversos fenômenos, bem como confirmar sua hipótese da importância do traumatismo, especialmente, o traumatismo sexual como fator patogênico.

Em 1932, Ferenczi inicia a escrita do seu Diário Clínico, ${ }^{7}$ no qual encontramos seu testemunho sobre o que ficou conhecido como análise mútua. Ferenczi comenta sobre a necessidade de naturalidade e honestidade do analista para com seu analisando. $\mathrm{O}$ autor

\footnotetext{
7 Segundo Dupont (1985/1990), o Diário Clínico de Ferenczi contém notas e comentários diários sobre a história de diferentes casos clínicos que forneceram subsídios para as reflexões do autor.
} 
descreve o caminho que percorreu até poder perceber que a revelação ao paciente da "falta de naturalidade", contida em sua "passividade", podia conduzi-lo mesmo à vida real e às suas resistências. Nesse sentido, relata que uma de suas pacientes exigiu que também tinha o direito de analisá-lo:

Num caso, essa comunicação dos conteúdos psíquicos próprios evoluiu efetivamente para uma espécie de análise mútua, da qual também eu, o analista, tirei grande proveito. Por certo, isso também me propiciou a ocasião de exprimir ideias e opiniões acerca do paciente que, de outro modo, nunca lhe chegariam aos ouvidos, por exemplo, comunicações desagradáveis de natureza moral ou estática, ou uma opinião relativa à paciente que eu escutei alhures, etc. Se podemos ensinar o paciente a suportar tudo isso, então o ajudamos a suportar mais coisas, aceleramos seu desligamento da análise e do analista, assim como a transformação das tendências para a repetição que não querem mudar. (Ferenczi, 1932/1990, p. 35)

Como destaca, em nota de 17 de janeiro de 1932, essa nova atitude adotada pelo analista possibilitou que o analisando falasse tudo que estava retido até então, de forma que todos os afetos viessem à tona. Segundo ele, quando o analista comunicava seus sentimentos e antipatias, havia um surpreendente apaziguamento no paciente e surgiam vários progressos no trabalho. $\mathrm{O}$ fato de o paciente ter que lidar com a contratransferência do analista favorecia a sua capacidade de suportar o desprazer que, no passado, conduziu ao recalcamento. Sobre os sucessos da análise mútua, o autor enfatiza: "É como se duas metades da alma se completassem para formar uma unidade. Os sentimentos do analista entrelaçam-se com as ideias do analisando e as ideias do analista (imagens de representações) com os sentimentos do analisando." (Ferenczi, 1932/1990, p. 45).

No entanto, os primeiros sucessos da análise mútua encontraram, com o decorrer do tempo, suas dificuldades. $\mathrm{O}$ autor percebeu que os pacientes passavam a dirigir sua atenção exclusivamente para o analista e para descobertas dos seus complexos. Entretanto, Ferenczi também questionou até onde essa nova técnica poderia ser rechaçada sem discussão. Ele confessa que parecia indigno agir como se tivesse se virado bem com a mutualidade e lembra que só conseguiu realizar sua própria autoanálise a partir de grande reserva mental. Ele foi percebendo que, algumas vezes, tinha o sentimento de ir longe demais, o que o ressentia. Assim, foi levado a falar abertamente sobre o aspecto fragmentário da sua participação na mutualidade e sobre a decisão de não prosseguir. Ferenczi (1932/1990, p. 154) conclui que a análise mútua seria: “[...] somente um recurso usado na falta de coisa melhor. Seria preferível uma análise autêntica por um estranho qualquer, sem nenhuma obrigação".

\section{Considerações Finais}

Diante da análise dos textos ferenczianos até 1912, podemos supor que o mecanismo da transferência seria o mesmo mecanismo da introjeção. A transferência é pensada como um processo a partir do qual os neuróticos tentam neutralizar os afetos flutuantes, transferindo-os para objetos do 
mundo externo e expandindo, assim, sua esfera de interesses, o seu ego. Nos textos dedicados ao tema da transferência que se seguem, observamos quão raras tornam-se as aparições do termo introjeção. Quando o menciona, o autor faz alusão às proposições encontradas nos trabalhos Transferência e introjeção (Ferenczi, 1909/2011) e O conceito de introjeção (Ferenczi, 1912/2011).

Com o passar dos anos, o interesse de Ferenczi voltou-se, cada vez mais, para modificações técnicas que pudessem auxiliá-lo no tratamento de pacientes difíceis, o que influenciou sua concepção da transferência e do seu manejo. Como vimos, o caminho percorrido, em suas elaborações técnicas, inicia-se com a técnica ativa, passa pela técnica de relaxamento, pela constatação da contratransferência, pela análise mútua e seu abandono.

Os desenvolvimentos técnicos e teóricos de Ferenczi foram, cada vez mais, distanciandose daqueles de Freud. O tratamento de pacientes graves o levou a perceber que a técnica psicanalítica clássica não era suficiente e que eram necessárias inúmeras adaptações e novos arranjos transferenciais. Dessa forma, ele buscou testar métodos e artifícios para neutralizar a energia afetiva dos complexos recalcados que estavam na base dos sintomas. Ferenczi denunciou o apego excessivamente rígido às técnicas psicanalíticas, em detrimento da intensidade do encontro afetivo propiciado pela transferência, a qual, para ele, deveria ser a base do dispositivo terapêutico.

A transferência passou a ser pensada considerando-se não somente os efeitos da relação analista-analisando sobre o paciente. Os sentimentos de ambos os lados passaram a ser apreciados e levados em consideração no trabalho psicanalítico, daí a necessidade da técnica de "esticar-se". Percebemos que o olhar de Ferenczi sobre a transferência possibilitou o desvendamento de toda uma trama conceitual e a descrição de fenômenos clínicos essenciais, até então pouco considerados, como a análise do próprio analista, a contratransferência e a transferência negativa.

\section{Referências}

Abras, R. M. G. (2014). Ferenczi: uma clínica a partir do traumático. Reverso, 36(67), 8589. Recuperado em 16 novembro, 2016, de http://pepsic.bvsalud.org/scielo.php?scri pt=sci_arttext\&pid $=$ S0102739520140001 00010\&lng $=$ pt\&tlng $=$ pt.

Balint, M. (1968/2011). Prefácio do Dr. Michaël Balint. In S. Ferenczi. Psicanálise I (Obras Completas, 2 a ed., pp. VII-X). São Paulo: Martins Fontes.

Balint, M. (1970/2011). Prefácio do Dr. Michaël Balint. In S. Ferenczi. Psicanálise II (Obras Completas, 2a ed., pp. IX-XIII). São Paulo: Martins Fontes.

Brusset, B. (2011). The Therapeutic Action of Psychoanalysis International Journal of Psychoanalysis, 93, 427-442. Recuperado em 21 novembro, 2017, de doi: 10.1111/j.1745-8315.2011.00512.

Casadore, M. M. (2012). Sándor Ferenczi e a Psicanálise: pela errância das experimentações. São Paulo: Cultura Acadêmica.

Coelho Junior, N. E. (2004). Ferenczi e a experiência da Einfüblung. Ágora: Estudos em Teoria Psicanalítica, 7(1), 73-85. Recuperado em 15 novembro, 2017, de https://dx.doi.org/10.1590/S151614982004000100005.

Dupont, J. (1985/1990). Prefácio. In S. Ferenczi. Diário clínico (pp. 11-27). São Paulo: Martins Fontes. 
Dupont, J. (1974/2011). Introdução. In S. Ferenczi. Psicanálise III (Obras Completas). São Paulo: Martins Fontes.

Falzeder, E., Brabant, E. \& Giampieri, P. (Orgs.). (1995). Sigmund Freud e Sándor Ferenczi: Correspondencia (Vol. 1, tomo 2 1912-1914, C. Cavalcanti \& S. Lages, Trad.). Rio de Janeiro: Imago Editora Ltda.

Ferenczi, S. (2011). Transferência e Introjeção. In S. Ferenczi. Psicanálise I (Obras Completas). São Paulo: Martins Fontes. (Trabalho original publicado em 1909).

Ferenczi, S. (2011). O conceito de introjeção. In S. Ferenczi. Psicanálise I (Obras Completas). São Paulo: Martins Fontes. (Trabalho original publicado em 1912).

Ferenczi, S. (2011). Progresso da teoria psicanalítica das neuroses (1907-13). In S. Ferenczi. Psicanálise II (Obras Completas). São Paulo: Martins Fontes. (Trabalho original publicado em 1914).

Ferenczi, S. (2011). A técnica psicanalítica. In S. Ferenczi. Psicanálise II (Obras Completas). São Paulo: Martins Fontes. (Trabalho original publicado em 1918).

Ferenczi, S. (2011). Dificuldades técnicas de uma análise de histeria. In S. Ferenczi.

Psicanálise III (Obras Completas). São Paulo: Martins Fontes. (Trabalho original publicado em 1919).

Ferenczi, S. (2011). Prolongamentos da "técnica ativa” em Psicanálise. In S. Ferenczi. Psicanálise III (Obras completas). São Paulo: Martins Fontes. (Trabalho original publicado em 1921).

Ferenczi, S. (2011). Contraindicações da técnica ativa. In S. Ferenczi. Psicanálise III (Obras Completas). São Paulo: Martins Fontes. (Trabalho original publicado em 1926).

Ferenczi, S. (2011). O problema do fim da análise. In S. Ferenczi. Psicanálise IV (Obras Completas). São Paulo: Martins Fontes. (Trabalho original publicado em 1928).
Ferenczi, S. (2011). Elasticidade da técnica psicanalítica. In S. Ferenczi. Psicanálise IV (Obras Completas). São Paulo: Martins Fontes. (Trabalho original publicado em 1928).

Ferenczi, S. (2011). Princípio de relaxamento e neocatarse. In S. Ferenczi. Psicanálise IV (Obras Completas). São Paulo: Martins Fontes. (Trabalho original publicado em 1930).

Ferenczi, S. (1990). Diário Clínico. São Paulo: Martins Fontes. (Trabalho original publicado em 1932).

Ferenczi, S. (2011). Confusão de línguas entre os adultos e a criança. In S. Ferenczi. Obras Completas: Psicanálise IV (Obras Completas). São Paulo: Martins Fontes. (Trabalho original publicado em 1933 [1932]).

Ferenczi, S., \& Rank, O. (2011). Perspectivas da Psicanálise. In S. Ferenczi. Psicanálise IV (Obras Completas). São Paulo: Martins Fontes. (Trabalho original publicado em 1924).

Freud, S., \& Breuer, J. (1996). Estudos sobre a histeria (Edição Standard Brasileira das Obras Psicológicas Completas de Sigmund Freud, vol. II). Rio de Janeiro: Imago.(Trabalho original publicado em 1895).

Freud, S. (1996). Fragmento da análise de um caso de histeria (Edição Standard Brasileira das Obras Psicológicas Completas de Sigmund Freud, vol. VII). Rio de Janeiro: Imago. (Trabalho original publicado em 1905[1901]).

Freud, S. (1996). A dinâmica da transferência (Edição Standard Brasileira das Obras Psicológicas Completas de Sigmund Freud, vol.. XII). Rio de Janeiro: Imago. (Trabalho original publicado em 1912).

Freud, S. (1996). Recordar, repetir e elaborar (Edição Standard Brasileira das Obras Psicológicas Completas de Sigmund Freud, vol. XII). Rio de Janeiro: Imago. (Trabalho original publicado em 1914). 
Hoffer, P. (2000). The Correspondence of Sigmund Freud and Sándor Ferenczi (Vol. 3, 1920 1933). Cambridge, Massachusetts: The Belknap Press of Harvard University Press.

Kupermann, D. (2008). Presença sensível: a experiência de transferência em Freud, Ferenczi e Winnicott. In D. Kupermann. Presença sensivel - cuidado e criação na clínica psicanalítica (pp. 83-108). Rio de Janeiro: Civilização Brasileira.

Kupermann, D. (2010). A via sensível da elaboração. Caminhos da clínica psicanalítica. Cadernos de Psicanálise, Círculo Psicanalítico RJ, 23, 31-45. Recuperado em 20 novembro, 2016, de http://www.freudiana.com.br/document os/CADERNOS-DEPSICANALISE_AviasensivelDaniel\%20Kupermann.pdf.

Laplanche, J., \& Pontalis, J.-B. (2001). Vocabulário da Psicanálise. São Paulo: Martins Fontes.

Maurano, D. (2006). A transferência: uma viagem rumo ao continente negro. Rio de Janeiro: Zahar.

Pinheiro, M. T. (1994). Trauma e melancolia. In C. S. Katz. Ferenczi: história, teoria, técnica. Rio de Janeiro: Editora 34.

Pinheiro, T. (2016). Ferençৃi. São Paulo: Casa do Psicólogo.

Pizzinga, V. H., \& Aran, M. (2009). Afeto, intensidade e confiança na experiência analítica: algumas considerações sobre a heterodoxia clínica de S. Ferenczi. Ágora: Estudos em Teoria Psicanalítica, 12(2), 319332. Recuperado em 16 outubro, 2017, de https:/ /dx.doi.org/10.1590/S151614982009000200011.

Rachman, A. W. (2007). Sándor Ferenczi's Contributions to the Evolution of Psychoanalysis. Psychoanalytic Psychology, 24(1), 74-96. Retrieved November 10,2017, from http:/ /dx.doi.org/10.1037/07369735.24.1 .74
Sanches, G. P. (1994). Sigmund Freud e Sándor Ferenczi. In S. A. Figueira (Org.). Contratransferência: de Freud aos contemporâneos. São Paulo: Casa do Psicólogo.

Verztman, J. S. (2002). O observador do mundo: a noção de clivagem em Ferenczi. Agora: Estudos em Teoria Psicanalítica, 5(1), 59-78. Recuperado em 16 outubro, 2017, de https://dx.doi.org/10.1590/S151614982002000100005.

Recebido em: 30/1/2018

Aprovado em: 2/5/2018 